Chronic Obstructive Pulmonary Diseases:

Journal of the COPD Foundation

FOUNDATION

\author{
Images in COPD
}

\title{
Images in COPD: Alpha-1 Antitrypsin Deficiency and Bronchiectasis
}

Scott Simpson, DO ${ }^{1}$ Friedrich Kueppers, $\mathrm{MD}^{2}$ Robert M. Steiner, $\mathrm{MD}^{1,2}$

\begin{abstract}
Abbreviations: forced expiratory volume in 1 second, $\mathbf{F E V}_{\mathbf{1}}$; forced vital capcity, FVC; alpha-1 antitrypsin deficiency, AATD; computed tomography, CT

Citation: Simpson S, Kueppers F, Steiner RM. Images in COPD: Alpha-1 antitrypsin deficiency and bronchiectasis. Chronic Obstr Pulm Dis (Miami). 2016;3(2):601-604. doi: http://dx.doi.org/10.15326/jcopdf.3.2.2016.0143
\end{abstract}

1 Department of Radiology, Temple University Health System, Philadelphia, Pennsylvania

2 Thoracic Medicine and Surgery, Temple University Health System Philadelphia, Pennsylvania

\section{Address correspondence to:}

Scott Simpson, DO

Email: scott.simpson@tuhs.temple.edu

\section{Case: Two brothers aged 70 (RS) and 72 (WS) each with a history of alpha - 1 antitrypsin deficiency are presented}

RS presented with a 10-year history of cough together with multiple episodes of bacteria-laden purulent sputum production. A diagnosis of bronchiectasis was confirmed by chest radiographs and CT (Figure 1). Pulmonary function tests showed no evidence of airway obstruction with a forced expiratory volume in 1 second $\left(F^{2} V_{1}\right)$ of $3.2 \mathrm{~L}$ (79\% of predicted) and a FEV 1 to forced vital capacity (FVC) ratio of 0.77 . Diffusing capacity for carbon monoxide was mildly decreased. The diagnosis of alpha-1 antitrypsin deficiency (AATD) (25mg/dl PI* ZZ) was made at age 66 and augmentation therapy was begun. Currently, his symptoms show improvement but intermittent exacerbations of purulent bronchitis still occur requiring antibiotic therapy.

WS has had a clinical profile of COPD for the last 10 years. Pulmonary function tests show moderately severe airway obstruction with an $\mathrm{FEV}_{1}$ between $47 \%$ and $59 \%$ of predicted. Chest radiographs and computed tomography (CT) showed evidence of panlobular emphysema (Figure 2). The most recent results show an $\mathrm{FEV}_{1}$ of $1.35 \mathrm{~L}$ (37\% of predicted) and a FEV $1 / F V C$ ratio of 0.57 . The diagnosis of AATD was made at age 67 (17mg/dl PI*ZZ). Augmentation therapy was begun following the diagnosis of his disease.

\section{Discussion}

In 1963, association between emphysema and AATD was described by Laurell and Eriksson. ${ }^{1}$ Since then, panlobular emphysema most frequently found in the lower lobes and to a lesser extent in the upper lobes has been most closely associated with AATD. ${ }^{2}$ Although airway disease including chronic bronchitis and bronchiectasis have been reported in patients with AATD, the relationship of airway disease has not been clearly defined nor has the incidence of bronchiectasis been clearly established. ${ }^{3-6}$ King et al in 1996 found CT evidence of bronchiectasis in 6 of 14 patients and 2 patients in this cohort demonstrated diffuse cystic bronchiectasis without predisposing conditions other than the history of AATD. ${ }^{4}$ The authors stressed the importance of including AATD in the differential diagnosis of bronchiectasis and suggested that the presence of bronchiectasis may be important if a single lung transplant is planned since bronchiectasis in the remaining lung may predispose to infection during the post-transplantation period. ${ }^{4}$ Parr et al in 2007 concluded that the prevalence of clinically significant bronchiectasis was greater than previously recognized in a series of 74 patients of whom 20 (27\%) had 


\section{Figure 1.}
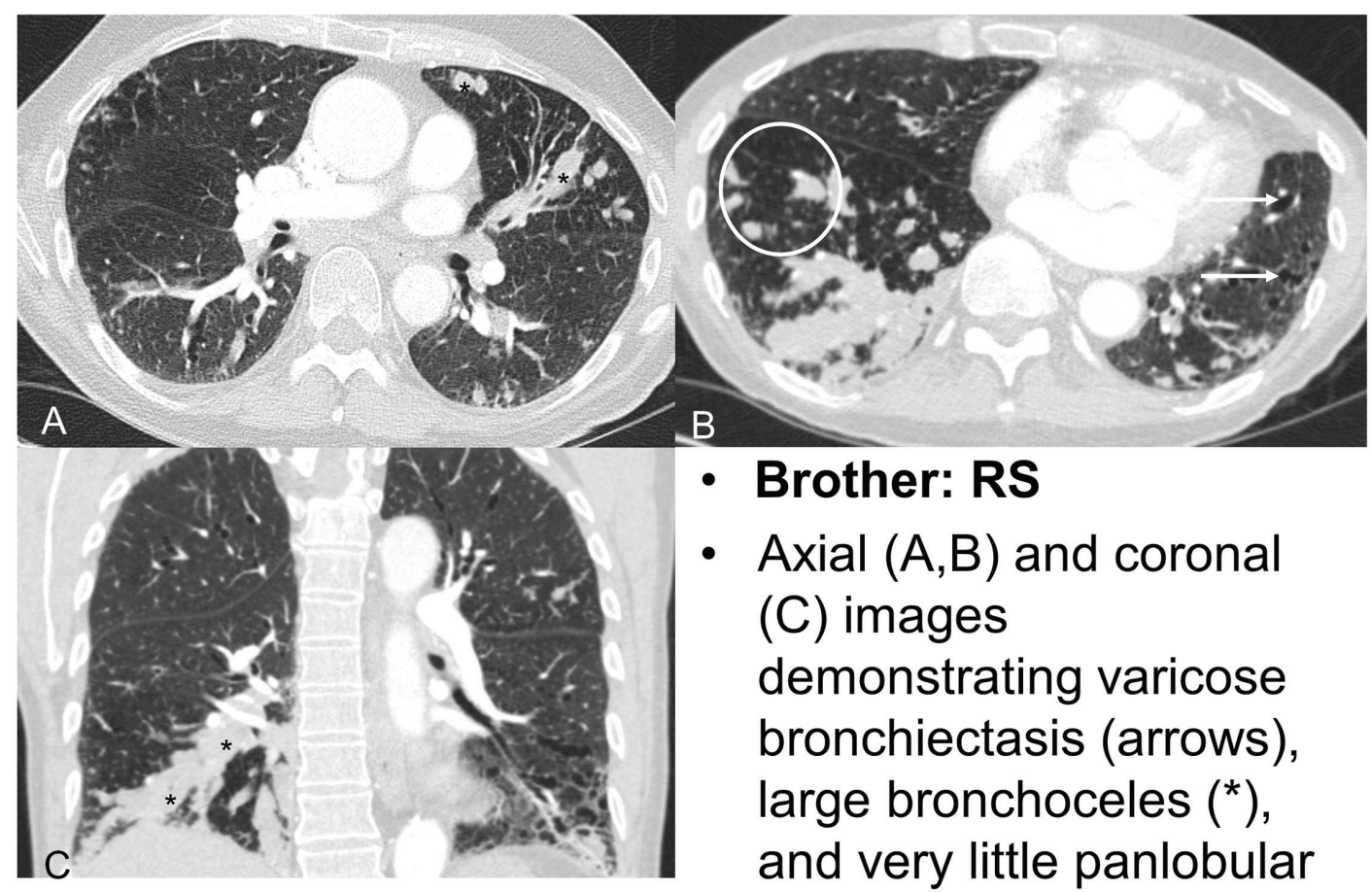

- Brother: RS

- Axial $(A, B)$ and coronal

(C) images

demonstrating varicose bronchiectasis (arrows), large bronchoceles (*), and very little panlobular emphysema (circle).

Figure 2.

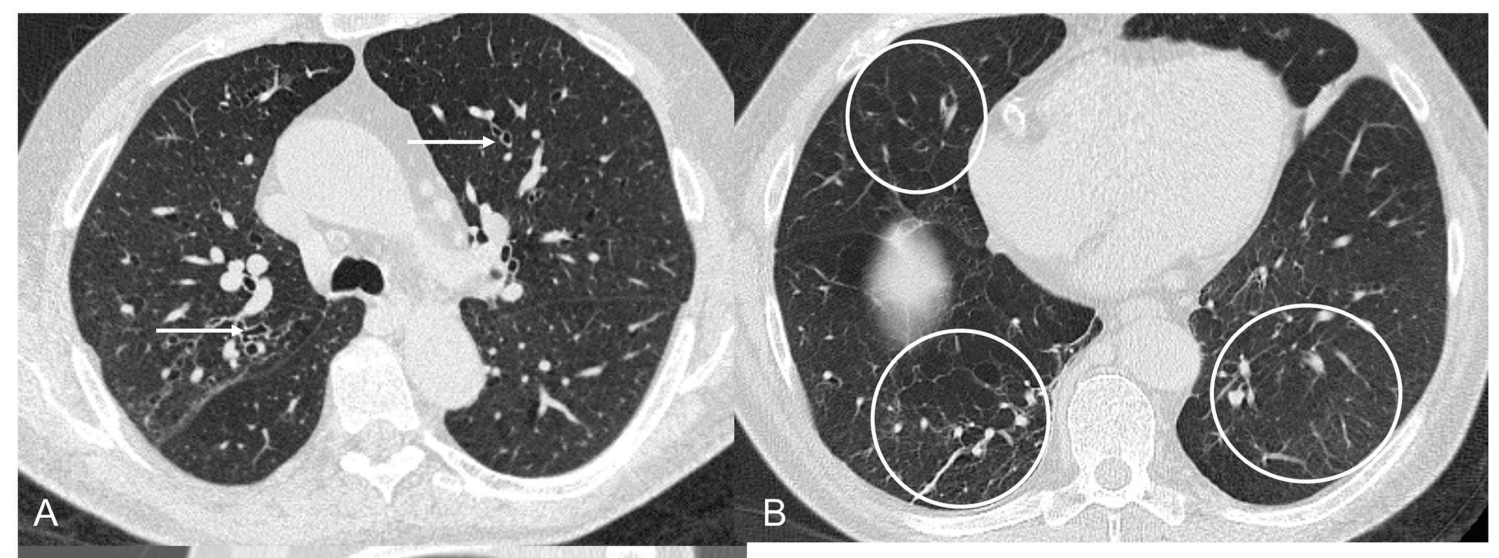

- Brother: WS

- Axial $(a, b)$ and sagittal images (c) reveal very mild bronchiectasis (arrows) and larger areas of panlobular emphysema (circles). 
radiologic evidence of bronchiectasis in 4 or more bronchopulmonary segments together with symptoms of regular sputum production. ${ }^{3}$

Two brothers are presented, one with predominately airway disease and evidence of bronchiectasis and the second with panlobular emphysema, little to no airway disease and pulmonary function test findings of obstructive disease. These cases illustrate the spectrum of CT findings in AATD. The presence of bronchiectasis with or without emphysema should alert the clinician to include AATD in the differential diagnosis. 


\section{References}

1. Eriksson S. Studies in alpha-1-antitrypsin deficiency. Acta Med Scand. 1965;177:1-85

2. Parr DG, Stoel BC, Stolk J, Stockley RA. Pattern of emphysema distribution in alpha-1-antitrypsin deficiency influences lung function impairment. Am J Respir Crit Care Med. 2004; 170(11): 1172-1178. doi: http://dx.doi.org/10.1164/rccm.200406-761OC

3. Parr DG, Guest PG, Reynolds JH, Dowson LJ, Stockley RA. Prevalence and impact of bronchiectasis in alpha-1 - antitrypsin deficiency. Am J Respir Crit Care Med. 2007;175 (12):1215-1221. doi: http://dx.doi.org/10.1164/rccm.200703-4890C

4. King MA, Stone JA, Diaz PT, Mueller CF, Becker WJ, Gadek JE. Alpha-1 - antitrypsin deficiency: evaluation of bronchiectasis with CT. Radiology. 1996;199:137-141

5. Cuvelier A, Muir JF, Hellot M-F, et al. Distribution of alpha-1 antitrypsin alleles in patients with bronchiectasis. Chest. 2000;117 (2):415-419.

doi: http://dx.doi.org/10.1378/chest.117.2.415

6. Shin MS, Ho KJ. Bronchiectasis in patients with alpha-1 antitrypsin deficiency: A rare occurance? Chest. 1992; 104 (5): 1384-1388. doi: http://dx.doi.org/10.1378/chest.104.5.1384 